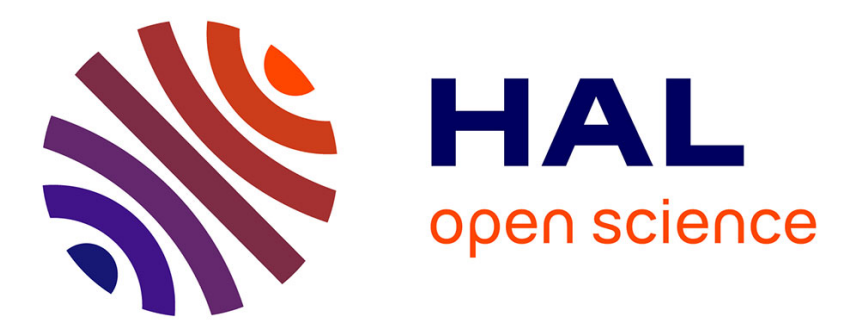

\title{
Physico-Chemical Properties of Nicotine and Nicotine-Bitterness Inhibitor Mixtures in Aqueous Solution and the Role of Water in their Taste
}

Vincent Aroulmoji, Mohamed Mathlouthi, M. O Portmann-Richardson

\section{- To cite this version:}

Vincent Aroulmoji, Mohamed Mathlouthi, M. O Portmann-Richardson. Physico-Chemical Properties of Nicotine and Nicotine-Bitterness Inhibitor Mixtures in Aqueous Solution and the Role of Water in their Taste. International journal of advanced Science and Engineering, 2021, 8 (2), pp.2136. 10.29294/IJASE.8.2.2021.2136-2146 . hal-03502242

\author{
HAL Id: hal-03502242 \\ https://hal.science/hal-03502242
}

Submitted on 24 Dec 2021

HAL is a multi-disciplinary open access archive for the deposit and dissemination of scientific research documents, whether they are published or not. The documents may come from teaching and research institutions in France or abroad, or from public or private research centers.
L'archive ouverte pluridisciplinaire HAL, est destinée au dépôt et à la diffusion de documents scientifiques de niveau recherche, publiés ou non, émanant des établissements d'enseignement et de recherche français ou étrangers, des laboratoires publics ou privés. 


\title{
Physico-Chemical Properties of Nicotine and Nicotine- Bitterness Inhibitor Mixtures in Aqueous Solution and the Role of Water in their Taste
} Vincent Aroulmoji ${ }^{1,2 *}$, Mohamed Mathlouthi ${ }^{1,3}$ and M.O. Portmann-Richardson ${ }^{4}$

${ }^{1}$ Laboratoire de Chimie Physique Industrielle, Faculté des Sciences, Université de Reims Champagne-Ardenne, BP1039, 51687 Reims Cedex 2, France ${ }^{2}$ Mahendra Engineering College, Mallasamudram - 637503, Namakkal District,Tamil Nadu, India.

${ }^{3}$ Association Andrew VanHook, 2 Rue Léon Patoux, F-51664 Reims Cedex 2, France ${ }^{4}$ GlaxoSmithkline Consumer Healthcare, St. George's Avenue, Weybridge, Surrey, KT13 0DE, United Kingdom

\begin{abstract}
The role of water in sweet taste chemoreception of small carbohydrates and artificial sweeteners was derived from physico-chemical methods and spectroscopic studies of their aqueous solutions. Likewise, surface tension, contact angles with a hydrophobic surface, and the adhesion forces to this type of surface of the aqueous solutions of sapid molecules were found to discriminate between their effects on water cohesion and also between their taste qualities. In the present study, surface tension (ST) and Apparent Specific volume (ASV) for bitter molecule (Nicotine) and bitterness inhibitors (sugars, polyols, salts) and Nicotine-Inhibitor mixtures were investigated at air-water interface using "dynamic surface tension" method in order to determine the role of water structure in the mechanism of unpleasant taste inhibition. The ST method was chosen since it provides reliable, sensitive and convenient means of investigating the adsorption of molecules at an interface. The ASV offer direct experimental verification of computed volumes and, measures of the effective volumes of sapid solutes in the vicinity of receptor sites. The value of Apparent Specific Volume (ASV) proves to be a good discriminator of tastes. The results of the present study allow to conclude that surface tension values are a good tool to classify inhibitors in three classes: molecules with antagonist effect (AMP) on Nicotine adsorption at the interface, molecules with negligible effect (Sucrose, Aspartame, Acesulfame-K, K-Gluconate, ?-Cyclodextrin), molecules with enhancement effect on the adsorption of Nicotine at air/solution interface (Maltitol, Palatinit ${ }^{\circledR}$, NaGluconate and Furaneol).
\end{abstract}

KEYWORDS: surface tension, Apparent Specific Volume, sweet, bitter, nicotine, taste masking, bitter suppression

https://doi.org/10.29294/IJASE.8.2.2021.2136-2146 C2021 Mahendrapublications.com, All rights reserved

\section{INTRODUCTION}

Taste is one of the chemical senses of human beings. In brief, taste is perceived when an aqueous solution of a chemical comes in contact with taste buds at the surface of the tongue. Taste buds are circular shaped papillae, and each bud possesses fifty to hundred taste cells. It is known that some cells respond more readily to sweet, bitter or salty taste. When a taste stimulant or tastant, interacts with taste proteins (called taste receptors) a chemical cascade involving ion channels open at the cell's surface causing electrical changes to occur, which in-turn results in signal reaching to the brain to register sense of taste. While the chemical that produces sour and salt taste act directly on ion channels; chemicals responsible for sweet and bitter tastes bind to taste receptors, invoking signals that result in opening and closing of ion channels [1].

It is known that sweet and bitter tastes interact very closely with each other and both are apparently mediated by G-protein-coupled receptors. For example, inhibition of sweet taste by inhibitors like lactisol or methyl-dichlorogalactoside originates from their bitterness [2]. The change in taste modalities (sweet, sweetbitter or bitter) for chlorinated sucrose may be explained by the physicochemical properties of their aqueous mixtures [3]. We have reported that sucrose interacts with the bitter compound caffeine [4] to mask bitterness and that such interaction can be interpreted using hydration properties of each sapid molecule and that of their mixtures. 
Recently, we have [5] confirmed the usefulness of Laser Raman spectroscopy to enhance the understanding of the role of water mobility in taste perception. The effect of unpleasant bitter substance (Nicotine), Inhibitors of bitterness like Sucrose, Maltitol, Aspartame, Cyclodextrin, NaGluconate, K-Gluconate and Acesulfame-K or Nicotine-Inhibitors mixtures on water structure was investigated. Laser Raman results were used to characterize the molecules such as sucrose, Nagluconate, K-gluconate, Cyclodextrin, Aspartame and Acesulfame-K as antagonists to the effect of Nicotine in ternary water-inhibitor-nicotine mixtures. Moreover, the results of volumetric methods, namely Apparent Specific Volume and Intrinsic viscosity support the modification of water structure around sweet, bitter (Nicotine) and sweet-bitter mixtures. The mechanism of inhibition of bitterness by sweet molecules may be credited to the arrangement of hydration water molecules which prove to be more mobile in the ternary mixture [6].

As a general rule, sweeteners are rather hydrophilic and bitter molecules have a predominant hydrophobic character. Because of the close relationship of sweet and bitter tastes and the possibility of assigning their taste modalities to their hydration properties, we decided to study physicochemical properties that may account for the hydrophilicity or hydrophobicity of the molecules of nicotine, bitterness inhibitors and their binary mixtures in aqueous medium. Also, electrical nature of taste signals and their dependence on ion transport, solution concentration and solute polarity incited us to focus our attention on the interactions of sweet and bitter molecules with water.

The aim of the study was to investigate molecular organisation of the sweet, bitter and sweet-bitter molecules at the air/solution interface by employing surface tension. This method was chosen since it provides reliable, sensitive and convenient means of investigating the adsorption of molecules at an interface. Also, this technique was successfully applied to study the reduction of bitterness intensity of bitter drugs Propantheline Bromide by Cyclodextrin [7]. An aqueous solution of Nicotine (bitter), potential inhibitors (sugars, polyols, salts) and NicotineInhibitor mixtures were investigated at air-water interface using "dynamic surface tension" method.

\section{MATERIALS AND METHODS}

\subsection{Chemicals Used}

Nicotine supplied by GSK was used without any prior treatment. The potential inhibitors such as Sucrose, Maltitol, Aspartame, Maltol, $\beta-$
Cyclodextrin, Na-Gluconate and K-Gluconate were from Sigma Chemicals and Acesulfame-K was a gift from Nutrinova, France. The other inhibitors namely Palatinit $^{\circledR}$ and Furaneol were also supplied by GSK. The chemicals $\left(\mathrm{NaHCO}_{3}\right.$, $\mathrm{K}_{2} \mathrm{HPO}_{4} 3 \mathrm{H}_{2} \mathrm{O}, \mathrm{NaCl}, \mathrm{KCl}, \mathrm{CaCl}_{2} .2 \mathrm{H}_{2} \mathrm{O}, \mathrm{NaN}_{3}$ ) used in preparation of artificial saliva were purchased from Sigma Chemicals and used without further purification.

\subsection{Sample Preparation}

The density parameter was used for calculation of apparent specific volume and apparent molar volume. The bitter compound nicotine, bitterness inhibitors and nicotine-inhibitor mixtures were prepared in artificial saliva $(\mathrm{pH}>8.2)$ in different proportions $(1: 1,1: 2,1: 1: 1$ ratio). Before measurements all solutions were filtered through a $0.22 \mu \mathrm{m}$ pore Millex Millipore filter. Each experimental analysis was repeated until constant values were obtained. Composition of artificial saliva was reported in a previous paper [8].

For surface tension studies, molar concentrations of nicotine and nicotine-inhibitor mixtures were prepared by dissolving the chemicals in Ches buffer (2-[N-Cyclohexylamino) ethane-sulfonic acid, $10 \mathrm{mM}$, with $\mathrm{pH}-8.62$ at $20^{\circ} \mathrm{C}$. All glass vessels used in the experiment were cleaned with chromosulfuric acid and rinsed thoroughly with ultra pure water (resistivity of $0.055 \Omega^{-1} \mathrm{~cm}^{-1}$, Maxima-HPLC grade). All samples before use were filtered through a $0.22 \mu \mathrm{m}$ pore Millex Millipore filter. The measurements were carried out at a constant temperature of $20^{\circ} \mathrm{C}$.

\subsection{Density Measurements}

Density values were determined using an Anton Paar Density Analyser (DMA 5000) from Paar Scientific Ltd, UK. Temperature was maintained at $25 \pm 0.02^{\circ} \mathrm{C}$. The density of sample was measured in an oscillating U-tube. The instrument was calibrated using air and distilled water. The accuracy of the instrument was found to be \pm 1 $\mathrm{x} 10^{-4} \mathrm{~g} / \mathrm{cm}^{3}$.

\subsection{Determination of Apparent Molar and Specific Volume}

The apparent molar volumes $\left(\phi_{\mathrm{v}} \mathrm{cm}^{3} / \mathrm{mol}\right)$ and apparent specific volumes (ASV $\mathrm{cm}^{3} / \mathrm{g}$ ) were calculated [9] from density values using equation (1) and (2): 


$$
\phi_{v}=\frac{1000\left(d_{0}-d\right)}{m d d_{0}}+\frac{M_{2}}{d}
$$

Where $d_{0}=$ density of solvent at one temperature $\left(\mathrm{g} / \mathrm{cm}^{3}\right) ; \mathrm{d}=$ density of solution at the same temperature $\left(\mathrm{g} / \mathrm{cm}^{3}\right) ; \mathrm{m}=$ molality of the solution (mol $/ \mathrm{kg})$; and $\mathrm{M}_{2}=$ molecular weight of solute (g/mol):

$$
A S V=\frac{\phi_{v}}{M_{2}}
$$

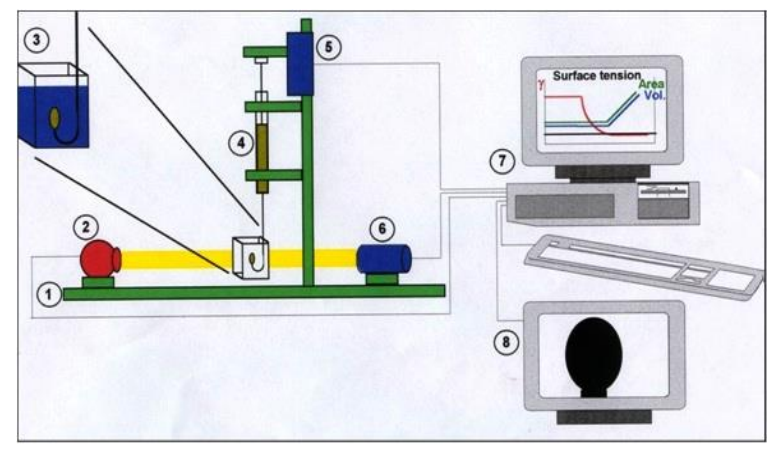

Figure.1 (A) Schematic Representation of Bubble Tensiometer

1. Optical Bench 2. Light Source 3. Experimental Cell 4. Micro Syringe Containing Drop Phase 5. DC Motor Driving 6. CCD Camera 7. Personal Computer 8. Video Monitor
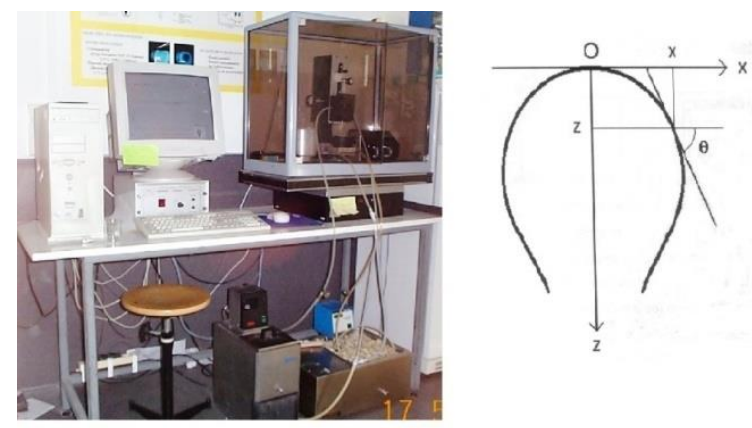

Figure.1 (B)

\subsection{Surface Tension measurements}

Figure 1(a) shows a diagram of experimental set up. An integrating sphere light source (2), a thermostated cuvette (3) containing liquid drop within a water phase and a charge coupling device (CCD camera) (7) attached to a telecentric lens (6) were aligned on an optical bench (1). An axisymmetric drop or bubble is formed at the tip of the needle of a syringe whose plunger position is controlled by a DC motor drive (5), into a $20^{\circ} \mathrm{C}$ temperature controlled optical glass cuvette $(1 \times 2 \times 4.3 \mathrm{~cm}$, Hellma, France) containing the sample (3). The syringe (4) is attached, through a Luer-lock device, to a U-shaped stainless steel laboratory pipetting canula (14G x 4 in., BectonDickinson, Franklin Lakes, USA) with a flat-cut tip having an external and internal diameter of 2 and $1 \mathrm{~mm}$ respectively. The material in contact with liquid is cleaned carefully with (diluted sulfochromic acid, doubly-distilled water, distilled alcohol and distilled chloroform) to prevent any contamination by tension active agents. Depending on the volume of the fluid, the drop is either mounted or left hanging. The equatorial drop diameter ranges from 4 to $6 \mathrm{~mm}$. After formation of drop, its profile is digitised and analysed through the CCD camera coupled to a video image profile digitiser board (Imaging Technology, model PC Vision Plus) connected to a personal computer. It is processed according to fundamental Laplace equation applied to a drop profile (Figure.1b).

$$
\frac{1}{x} \frac{d}{d x}(x \operatorname{Sin} \theta)=\frac{2}{b}-c z
$$

where $\mathrm{x}$ and $\mathrm{z}$ are Cartesian co-ordinates at any point on the drop profile, $b$ is radius of curvature at drop apex, $\theta$ is angle of tangent to drop profile and $\mathrm{C}$ is capillarity constant (equal to $(\mathrm{g} \times \Delta \rho) / \gamma$, where $\Delta \rho$ is difference between volume of two fluids, $\gamma$ the interfacial tension and $g$ is the acceleration of gravity). The computer computes the respective characteristic parameters of the drop; namely area, volume and interfacial tension $\left(\gamma_{0} / w\right)$ several times per second. The control unit can either record and plot changes in $\gamma_{0} / w$ as a function of time (non-regulated mode) or maintain $\gamma_{0} / w$ at a constant end-point value (barostatic regulation mode) by exerting a feedback regulation on DC motor, which automatically increases drop volume with time.

\section{RESULTS ARD DISCUSSION 3.1. Surface Properties}

Short-range forces of attraction (Vander Waals forces, London dispersion forces) exist between molecules; they are responsible for the existence of liquid state. Surface and interfacial tension are readily explained in terms of these forces. Surface tension is thus a measure of molecular cohesion or compression. Interfacial properties such as surface tension and contact angle measurements can be used as predictive tools for sweetness determination of potency or synergy of sweet molecules [8]. 


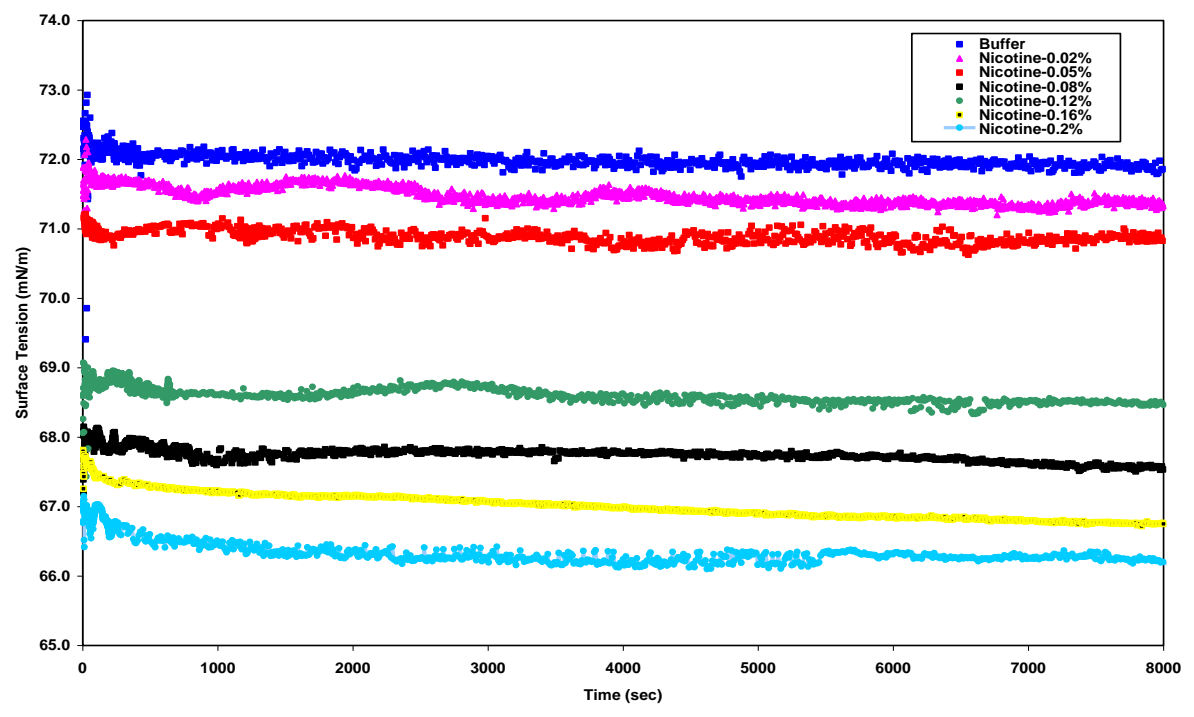

Figure 2. Effect of increasing concentration of Nicotine on its surface tension kinetics at a temperature of $20^{\circ} \mathrm{C}$. The kinetic surface tension values were measured in these solutions using IT Concepts Tensiometer as described in the experimental section

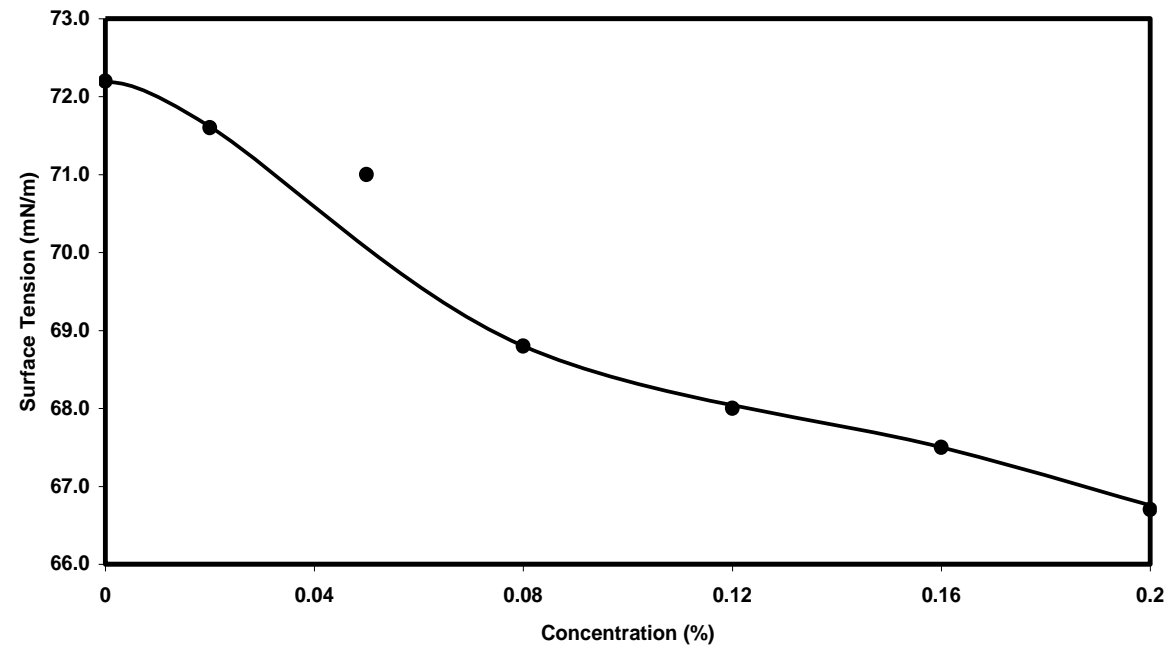

Figure.3. Surface Tension of Nicotine as a function of Concentration

\subsubsection{Kinetic Surface Properties of Pure Nicotine}

The experimental results of surface tension $(\gamma)$ kinetics of pure nicotine with increasing concentrations $(0.02$ to $0.2 \% \mathrm{w} / \mathrm{v})$ in Ches buffer solution is shown in Figures $2 \& 3$. All the surface tension measurements were carried out in buffered solution (Ches, $\mathrm{pH}$ 8.62) at a fixed temperature of $20^{\circ} \mathrm{C}$. At this $\mathrm{pH}$, the neutral form of nicotine is preponderant. In Figure 2 the surface tension $(\gamma)$ kinetics results of pure buffer solution are also reported for comparison. Figure 2 shows that pure buffer and nicotine solution have a higher stability of the surface tension over five hours from purification of the commercial products used in the present study. In pure buffered solution the surface tension $(\gamma)$ value was
$72.1 \mathrm{mN} / \mathrm{m}$, which is in good agreement with values reported in the literature. However, the presence of nicotine in buffered water causes an appreciable decrease in surface tension from 71.5 $\mathrm{mN} / \mathrm{m}$ to $66.5 \mathrm{mN} / \mathrm{m}$ with increase in volume concentration ranging from $0.02 \% \mathrm{w} / \mathrm{v}$ to $0.2 \%$ $\mathrm{w} / \mathrm{v}$. The higher concentration proportionately increases the adsorption at the air-solution interface and stabilises it over time (Figure 2). This detergent effect is related to a relatively high concentration of solute at the water/air interface. It is due to the orientation of lipophilic groups towards the solution surface. This behaviour is observed with other bitter tasting molecules like caffeine or propantheline bromide in aqueous solutions $[4,7]$. 
Table.1. Surface Tension $(\gamma, \mathrm{mN} / \mathrm{m})$ values for selected potential inhibitors in Water (Ches, $\mathrm{pH}=8.62)$ at $20^{\circ} \mathrm{C}$ (Nicotine $=0.05 \%$ and Inhibitors $\left.=0.1 \% \mathrm{w} / \mathrm{v}\right)$

\begin{tabular}{|l|c|}
\hline \multicolumn{1}{|c|}{ Compound } & $\begin{array}{c}\text { Surface Tension } \\
\text { (mN/m) }\end{array}$ \\
\hline Buffer (Ches) & 72.1 \\
\hline Nicotine (Pure) & 71.0 \\
\hline Sucrose & 72.8 \\
\hline Maltitol & 71.5 \\
\hline Palatinit & 71.1 \\
\hline Aspartame & 72.2 \\
\hline Acesulfame-K & 72.0 \\
\hline Maltol & 70.2 \\
\hline Furaneol & 71.2 \\
\hline Na-Gluconate & 72.2 \\
\hline K-Gluconate & 72.3 \\
\hline b-Cyclodextrin & 72.2 \\
\hline AMP & 71.0 \\
\hline
\end{tabular}

\subsubsection{Kinetic Surface Properties of Selected Inhibitors}

Surface tension $(\gamma)$ results are reported in Table 1 for the selected bitterness inhibitors Sucrose, Maltitol, Palatinit ${ }^{\circledR}$, Aspartame, Acesulfame-K, Maltol, Furaneol, Adenosine Monophophate (AMP), Na-gluconate, K-gluconate and $\beta$ Cyclodextrin in buffered water. In Table 1 a slight increase in the values of surface tension of sucrose (72.1 to $72.8 \mathrm{mN} / \mathrm{m}$ ) as compared to pure buffered water, is observed. It appears that a pure hydrophilic molecule like sucrose without surface active property remains in solution and tends to form a depletion layer at air/liquid interface. This phenomenon is common to sugars in aqueous solutions and creates a strong cohesion in watersugar hydrogen bonding [10]. On the other hand, the surface tension results obtained for Maltitol $(71.5 \mathrm{mN} / \mathrm{m})$ and Palatinit ${ }^{\circledR}(71.1 \mathrm{mN} / \mathrm{m})$ is slightly decreased as compared to pure buffered solution $(72.1 \mathrm{mN} / \mathrm{m})$. This difference in surface tension results may be due to purity of the samples, as mentioned in our previous report for Palatinit $^{\circledR}$, which is not a pure single molecule.

The aqueous solutions of artificial sweeteners namely Aspartame and Acesulfame- $K$ have comparable surface tension with water (72.2 and $72.0 \mathrm{mN} / \mathrm{m}$ against $72.1 \mathrm{mN} / \mathrm{m}$ for buffer) and are also stable over a period of time (see Figures). The surface tension kinetics values $(\gamma)$ of two flavour enhancers, namely Maltol and Furaneol (70.2 $\mathrm{mN} / \mathrm{m}$ and $71.2 \mathrm{mN} / \mathrm{m}$ ) were less tensioactive than buffered water $(72.2 \mathrm{mN} / \mathrm{m})$. This difference in surface tension may be due to the purity of the samples and also to their hydrophobicity. Moreover, Furaneol a volatile compound is a mixture of two compounds.
The surface tension $(\gamma)$ results of potential bitterness inhibitors (Adenosine Mono Phosphate (AMP), Na-gluconate, $\mathrm{K}$ - gluconate and $\beta$ Cyclodextrin) are reported in Table 1 . The results of the kinetics of surface tension $(\gamma)$ for these potential inhibitors are also shown in Figures 411. This result indicates that K-gluconate and $\beta$ Cyclodextrin do not appreciably modify values of surface tension $(\gamma)$ as compared to buffered water, whereas, Na-gluconate was found to be slightly higher as compared to buffered water under identical experimental conditions.

To summarise, our experimental results of surface tension $(\gamma)$ and surface properties of pure carbohydrates, intense sweeteners, flavour enhancers and organic salts are not significantly modified as compared to that of pure buffered water. This means that potential bitterness inhibitors are not notably surface active except for slight changes, which is very likely due to the preponderance of the hydrophilicity of these molecules at the origin of their water structure maker ability.

\subsubsection{Kinetic Surface Properties of Nicotine - Inhibitor Mixtures}

It may be recalled that nicotine is a surfaceactive compound and its adsorption at air/solution interface depends on its concentration, temperature and $\mathrm{pH}$. The present experiment aims at the study of the effect of potential inhibitors on nicotine solution prepared in buffer ( $\mathrm{pH}$ 8.62) in order to investigate the modification of unpleasant taste of nicotine in presence of these inhibitors (1:2 ratio) at the air/solution interface, which can occur at the receptor membrane surface as well. 


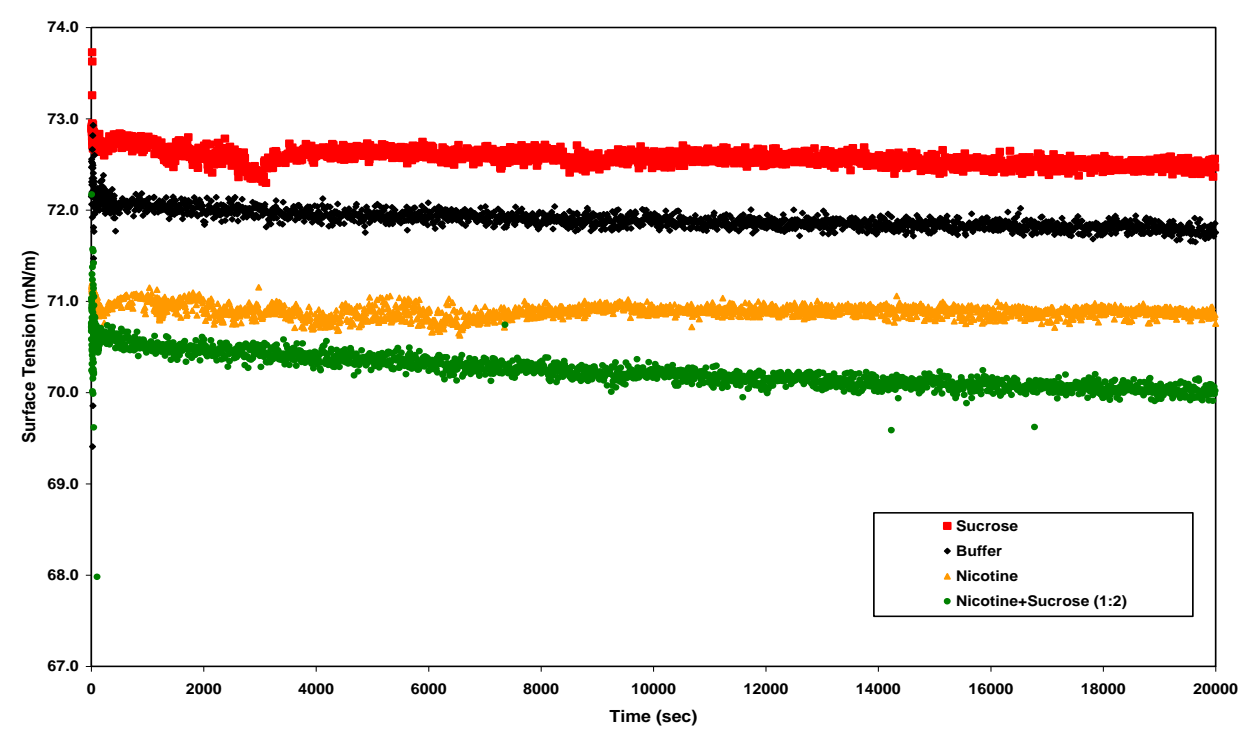

Figure.4. Surface Tension kinetics of Sucrose, Nicotine and Nicotine-Sucrose Mixtures at air/water Interface

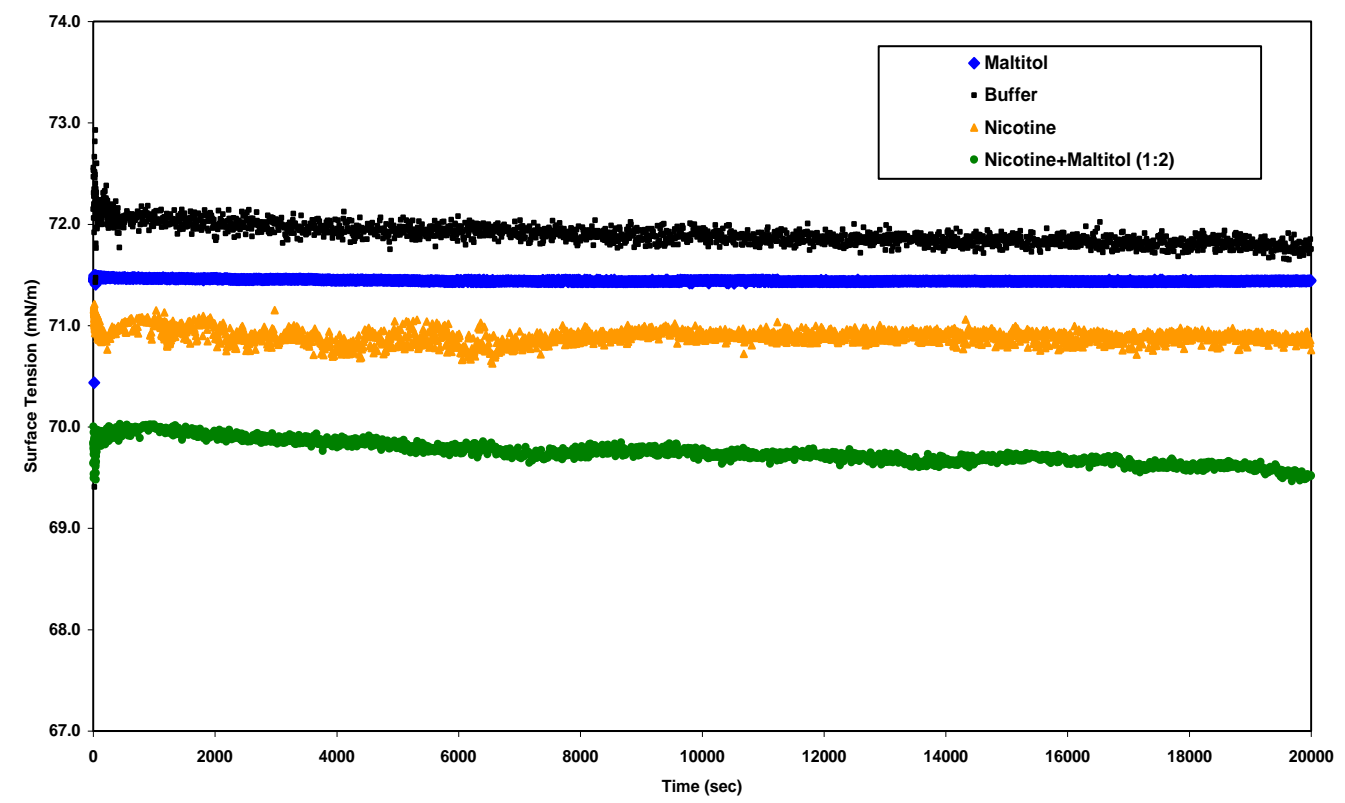

Figure.5. Surface Tension kinetics of Maltitol, Nicotine and Nicotine-Maltitol Miwtures at air/solution interface

The kinetic behaviour of surface tension $(\gamma)$ for pure nicotine $(0.05 \% \mathrm{w} / \mathrm{v})$ and nicotine - inhibitor (Sucrose, Maltitol, Palatinit $^{\circledR}$, Aspartame, Acesulfame-K, Moltol, Furaneol, AMP, NaGluconate, K-Gluconate, $\beta$-Cyclodextrin) mixtures are shown in Figures 4-12.

As a general rule the inhibitor molecules tend to interact with nicotine to modify its adsorption behaviour. We classify the effects of inhibitors:
$>$ as having an antagonist effect or depletion (increase of $(\gamma)$ example: AMP) (see Figure 11)

$>$ a negligible effect on $(\gamma)$, example: Sucrose, Aspartame, Acesulfame-K, KGluconate and $\beta$-Cyclodextrin.

$>$ an enhancement of adsorption effect $(\gamma)$, example: Maltitol, Palatinit $^{\circledR}$, NaGluconate and Furaneol.

To explain the three behaviours, we propose: that:

\section{Aroulmoji et al.,}


a). The mixing of AMP with nicotine in aqueous medium strengthens the internal bonds of water molecules at the air/water interface. The complex AMP-Nicotine, although hydrophobic tends to organise water structure at the interface in such a way that water molecules stay at the surface of sample and the complex is situated at a lower level (this phenomenon is called depletion). In other words, AMP inhibits the tendency of Nicotine to adsorb at the interface.

b).Molecules like Sucrose, Aspartame, AcesulfameK, K-Gluconate and ?-Cyclodextrin at equilibrium in mixtures with Nicotine reach a value of $\approx 70$ $\mathrm{mN} / \mathrm{m}$ while the initial value of pure Nicotine is 71 $\mathrm{mN} / \mathrm{m}$. Such an effect on the surface property $(\gamma)$ is almost negligible. This means that although these molecules have an initial surface tension comparable or slightly above that of buffer (they do not show a tendency to adsorb). When they are mixed with Nicotine, they have no antagonist effect and the adsorption at the air/solution interface is slightly decreased ( 71 to $70 \mathrm{mN} / \mathrm{m}$ ).

c). The behaviour of the rest of inhibitors (Maltitol, Palatinit $^{\circledR}$, Na-Gluconate and Furaneol) is clearly an enhancer effect of the adsorption of nicotine at the interface. This means that the presence of 1:2 mixture (Nicotine: Inhibitor) with Nicotine $=50$ $\mathrm{mg}$ in water contributes to form an adsorption layer

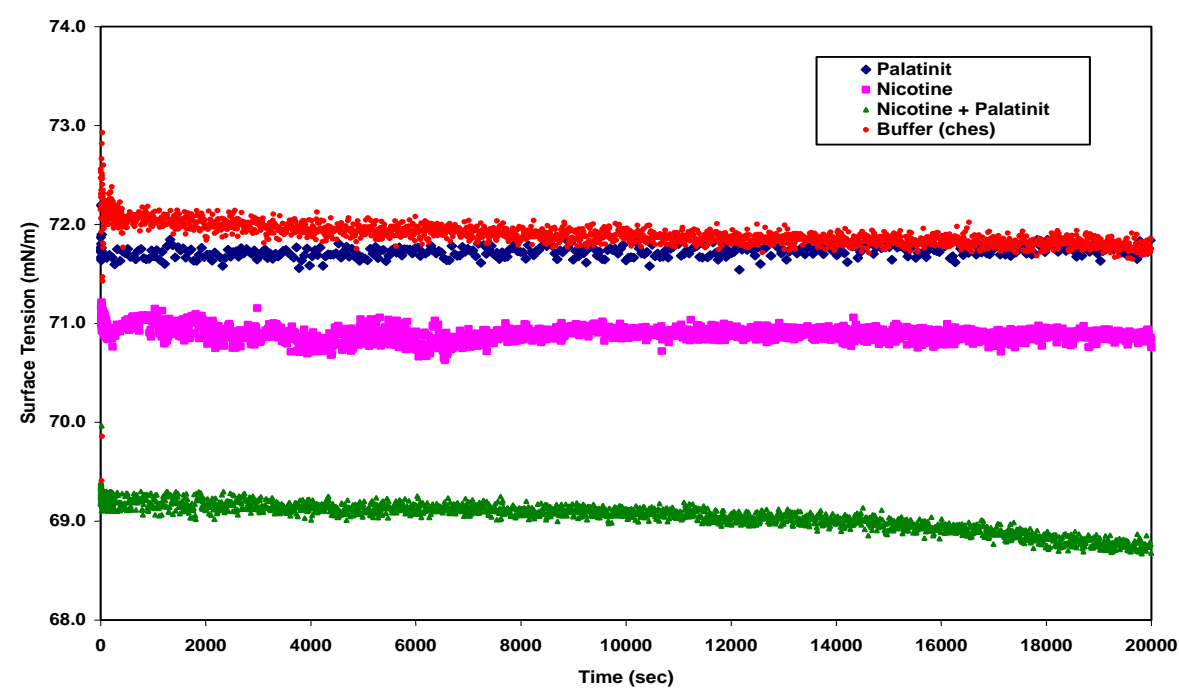

Figure.6. Surface Tension kinetics of Palatinit, Nicotine and Nicotine-Palatinit Mixtures at air-water Interface

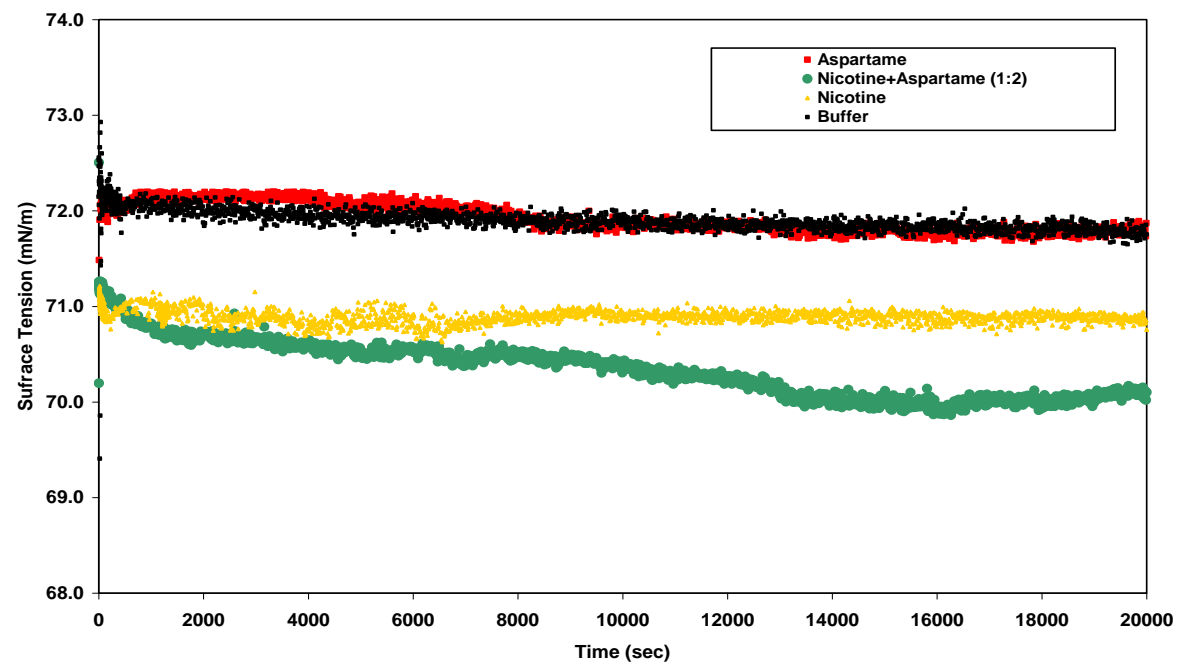

Figure.7 Surface Tension kinetics of Aspartame, Nicotine and Nicotine-Aspartame Mixtures at air/water Interface 


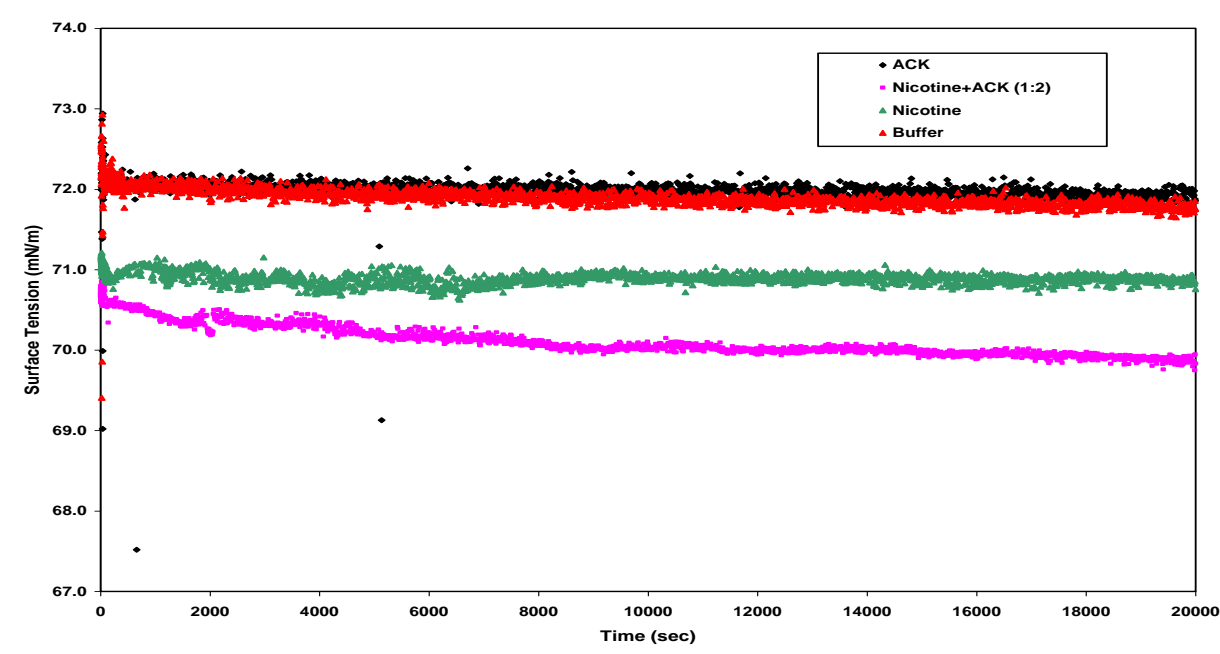

Figure.8. Surface Tension kinetics of Acesulfame-K, Nicotine and Nicotine-Acesulfame-K at air/water Interface

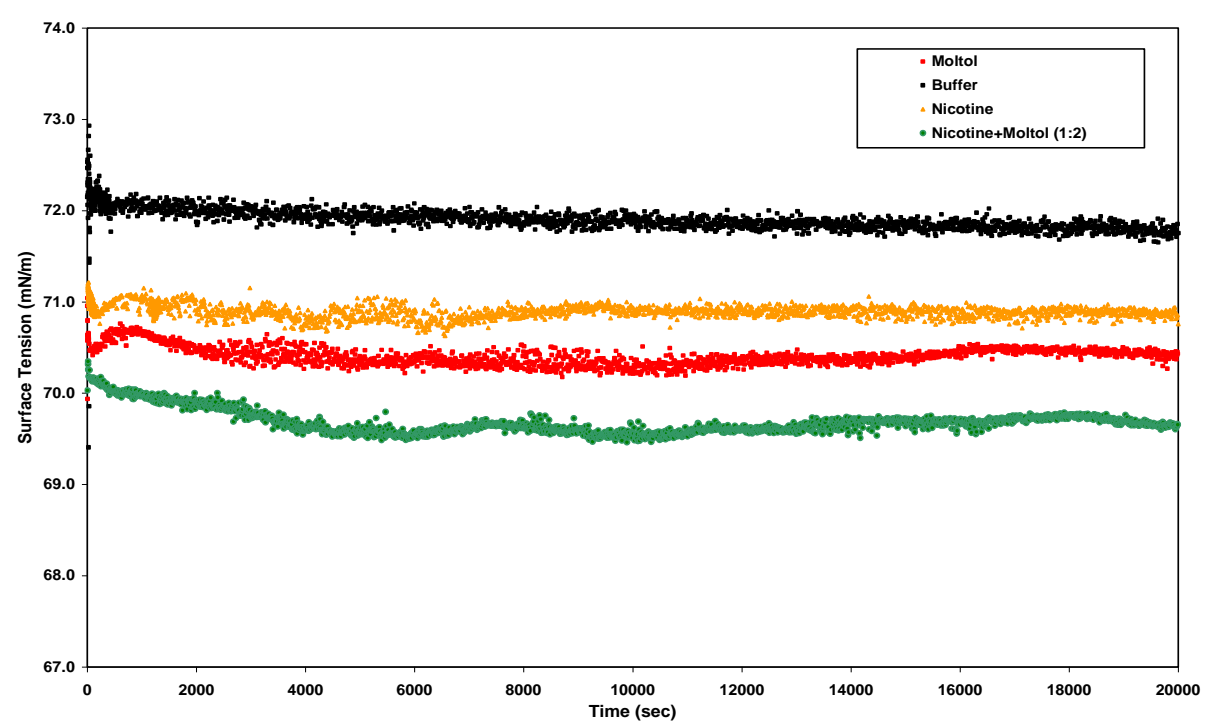

Figure.9. Surface Tension kinetics of Maltol, Nicotine and Nicotine-Maltol Mixtures at air/water Interface

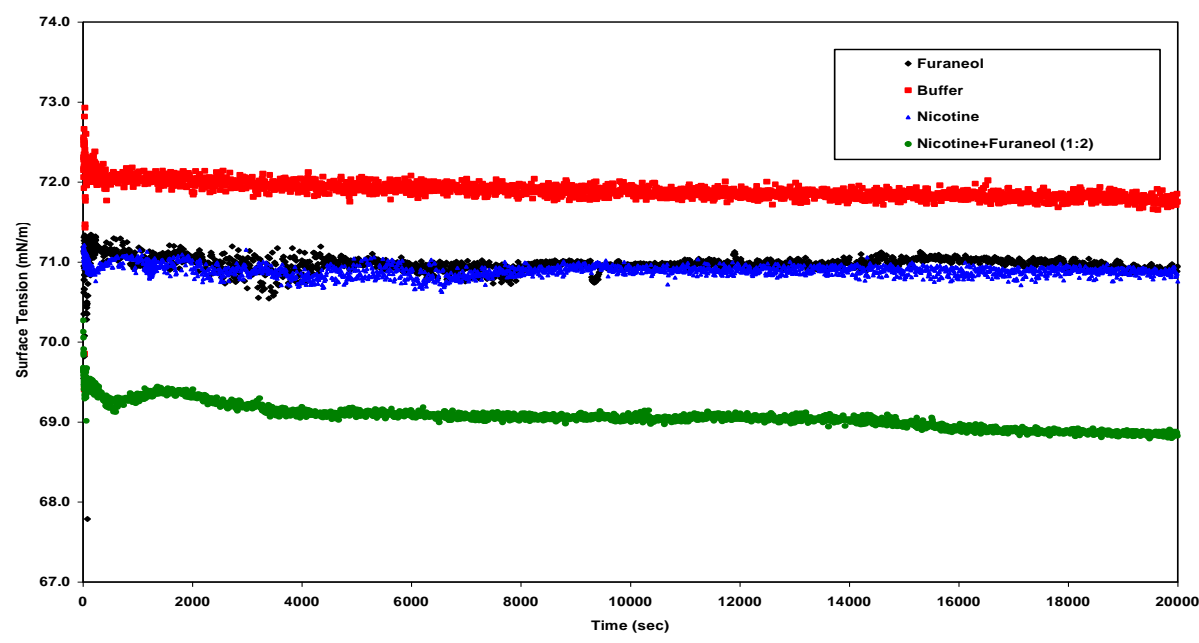

Figure.10. Surface Tension kinetics of Furaneol, Nicotine and Nicotine-Furaneol Mixtures at air/water Interface 


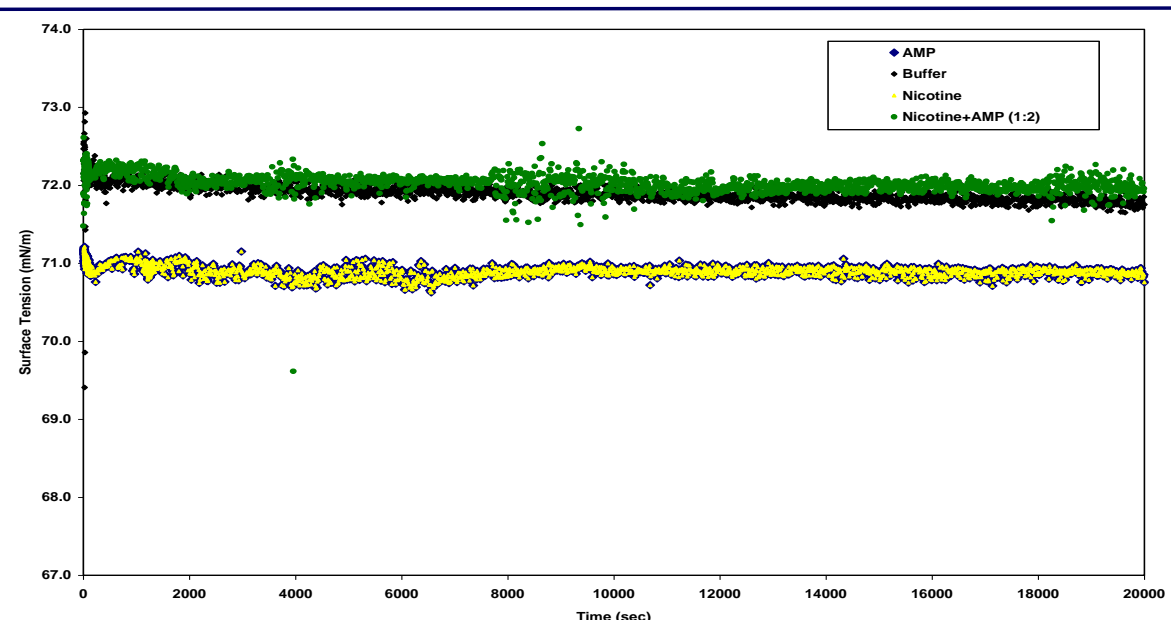

Figure.11. Surface Tension kinetics of AMP, Nicotine and Nicotine-AMP Mixtures at air/water Interface

\subsection{Formulation and ASV of Nicotine-Inhibitor Mixtures}

The value of Apparent Specific Volume (ASV) was found [11] to work as a good discriminator for tastes of sapid molecules with more than one sapophore. The efficiency of inhibitors may be tested by their aptitude to lower the ASV value of Nicotine from the bitter/volatile region $(0.997$ $\mathrm{cm}^{3} \mathrm{~g}^{-1}$ ) to that of the sweet region $(0.52-0.71$ $\mathrm{cm}^{3} \mathrm{~g}^{-1}$ ).

Based on sensorial studies reported by Burgard et al (see US Patent No:09/810, 815) [12] using mixtures of Acesulfame-K and/or Aspartame with the ratio $1: 1$ with nicotine (bitter compound) leads to mask unpleasantly bitter after taste. Based on this we have carried out detailed volumetric study in the same ratio (1:1) as well as different combinations of Nicotine-Inhibitor (1:1, $1: 2,1: 1: 1$ ratio) mixtures prepared in artificial saliva at a temperature of $25^{\circ}$. The results are reported in Table 2-5.

Table 2 lists the AMV and ASV results of Nicotine and Nicotine-Inhibitor mixtures (1:1 ratio). It may be seen from Table 2, ASV values of nicotine falls on the upper border of bitter region. Nicotine in presence of Inhibitors such as Sucrose, Palatinit ${ }^{\circledR}$, Maltitol, AMP, Beta-Cyclodextrin and Furaneol does not change in the ASV values as compared to pure Nicotine. The presence of Na-gluconate, Kgluconate and Acesulfame-K in Nicotine solution tends to shift ASV value of Nicotine from bitter region (0.7-0.9 $\left.\mathrm{cm}^{3} \mathrm{~g}^{-1}\right)$ to sweet region (0.5$0.7 \mathrm{~cm}^{3} \mathrm{~g}^{-1}$ ). The ASV values of Nicotine - Aspartame and Nicotine-Maltol were found to be $0.819 \mathrm{~cm}^{3} \mathrm{~g}^{-1}$ and $0.827 \mathrm{~cm}^{3} \mathrm{~g}^{-1}$, which fall at the center of the bitter region.

The ASV and AMV values calculated from density data for nicotine-inhibitor mixtures (1:2 ratio) are reported in Table 3 . The results indicate that in Nicotine solution the addition of Sucrose, Na-Gluconate, K-Gluconate and Acesulfame-K tend to shift the ASV value of Nicotine from bitter region to sweet region. The presence of AMP, Furaneol and $\beta$-Cyclodextrin in Nicotine solution does not modify ASV value of Nicotine. The ASV values for Nicotine- Maltol, Nicotine- Palatinit ${ }^{\circledR}$ and Nicotine-Maltitol mixtures were found to be $0.795 \mathrm{~cm}^{3} \mathrm{~g}^{-1}, 0.734 \mathrm{~cm}^{3} \mathrm{~g}^{-1}$ and $0.729 \mathrm{~cm}^{3} \mathrm{~g}^{-1}$, which is an appreciable lowering from the upper limit of bitter range to nearly the upper limit of sweet region. From these results (1:2 ratio) we conclude that sucrose, Na-Gluconate, K-Gluconate and Acesulfame- $\mathrm{K}$ are the most efficient bitterness inhibitors, although other molecules (Maltol, Maltitol, Palatinit ${ }^{\circledR}$ ) have a certain effect on ASV.

The ASV and AMV calculated for ternary mixtures (1:1:1 ratio) prepared in artificial saliva are reported in Table 4 . The ternary mixtures were prepared by fixing two compounds namely Nicotine + Acesulfame-K (1:1 ratio) as constant and changing the other potential inhibitors in order to understand the packing characteristic of solute in water structure. Mixing $\beta$-Cyclodextrin and Maltol to Nicotine + Acesulfame-K (ASV=0.718 $\mathrm{cm}^{3} \mathrm{~g}^{-1}$ ) mixture does not provoke any change in ASV values, whereas, the ASV values of Nicotine + Acesulfame-K+ Aspartame and Nicotine + Acesulfame-K + Furaneol still occur in the bitter region, but at much lower value then pure Nicotine.

As a general rule, a decrease in ASV means a better inhibition of Nicotine taste. From Table 4, it may be observed that in mixtures of Nicotine + Acesulfame-K, the addition of selected inhibitors namely K-gluconate, Na-gluconate, Palatinit ${ }^{\circledR}$, Sucrose, Maltitol and AMP greatly modifies ASV values of pure Nicotine as well as Nicotine + 
Acesulfame-K mixtures in artificial saliva. If our classification of inhibition efficiency is based on this parameter we have: Nicotine+ Acesulfame- $\mathrm{K}+$ K-Gluconate $>$ Nicotine+ Acesulfame-K $+\mathrm{Na}-$ gluconate $>$ Nicotine + Acesulfame-K + Palatinit $^{\circledR}>$ Nicotine+ Acesulfame-K + Maltitol $\approx$ Nicotine+ Acesulfame-K + Sucrose $>$ Nicotine+ Acesulfame$\mathrm{K}+\mathrm{AMP}$. Our results of ternary systems lead to the conclusion that Na-gluconate and K- gluconate are effective in suppressing bitterness of nicotine.

The rationale was based on the mechanism of bitterness suppression by salts. This is probably due to ionic structuring of water and 'favourable' hydration of bitter solutes leading to lower accessibility of the bitter molecules to its respective receptors.

Table.2. Apparent Molar Volume, Apparent Specific Volume of Nicotine and Nicotine-Inhibitor (1:1 ratio) Mixtures at $25^{\circ} \mathrm{C}$ in Artificial Saliva

\begin{tabular}{|l|c|c|}
\hline & AMV $\left(\mathbf{c m}^{3} / \mathbf{m o l}\right)$ & ASV $\left(\mathbf{c m}^{3} / \mathbf{g}\right)$ \\
\hline Nicotine & 162 & 0.997 \\
\hline Nicotine+Sucrose & 251 & 0.997 \\
\hline Nicotine+Na-Gluconate & 130 & 0.687 \\
\hline Nicotine+K-Gluconate & 139 & 0.703 \\
\hline Nicotine+Maltol & 119 & 0.827 \\
\hline Nicotine+Palatinit & 252 & 0.997 \\
\hline Nicotine+Maltitol & 253 & 0.997 \\
\hline Nicotine+AMP & 346 & 0.997 \\
\hline Nicotine+Aspartame & 187 & 0.819 \\
\hline Nicotine+Furaneol & 133 & 0.916 \\
\hline Nicotine+Acesulfame-K & 130 & 0.718 \\
\hline Nicotine+ $\beta$-Cyclodextrin & 646 & 0.997 \\
\hline
\end{tabular}

Table.3. Apparent Molar Volume, Apparent Specific Volume of Nicotine and Nicotine-Inhibitor (1:2 ratio) Mixtures at $25^{\circ} \mathrm{C}$ in Artificial Saliva

\begin{tabular}{|c|c|c|}
\hline & $\operatorname{AMV}\left(\mathrm{cm}^{3} / \mathrm{mol}\right)$ & $\operatorname{ASV}\left(\mathrm{cm}^{3} / \mathrm{g}\right)$ \\
\hline Nicotine & 162 & 0.997 \\
\hline Nicotine+Sucrose & 179 & 0.713 \\
\hline Nicotine+Na-Gluconate & 126 & 0.664 \\
\hline Nicotine+K-Gluconate & 131 & 0.664 \\
\hline Nicotine+Maltol & 144 & 0.795 \\
\hline Nicotine+Palatinit & 185 & 0.734 \\
\hline Nicotine+Maltitol & 185 & 0.729 \\
\hline Nicotine+AMP & 345 & 0.996 \\
\hline Nicotine+Aspartame & 187 & 0.819 \\
\hline Nicotine+Furaneol & 145 & 0.997 \\
\hline Nicotine+Acesulfame-K & 121 & 0.665 \\
\hline Nicotine $+\beta$-Cyclodextrin & 646 & 0.996 \\
\hline
\end{tabular}

Table.4. Apparent Molar Volume, Apparent Specific Volume of Nicotine and Nicotine-Inhibitor (1:1:1 ratio) Mixtures at $25^{\circ} \mathrm{C}$ in Artificial Saliva

\begin{tabular}{|l|c|c|}
\hline & AMV $\left(\mathbf{c m}^{3} / \mathbf{m o l}\right)$ & ASV $\left(\mathbf{c m}^{3} / \mathbf{g}\right)$ \\
\hline Nicotine & 162 & 0.997 \\
\hline Nicotine+ Acesulfame-K +Sucrose & 162 & 0.691 \\
\hline Nicotine+ Acesulfame-K +Na-Gluconate & 126 & 0.651 \\
\hline Nicotine+ Acesulfame-K +K-Gluconate & 129 & 0.648 \\
\hline Nicotine+ Acesulfame-K +Maltol & 161 & 0.995 \\
\hline Nicotine+ Asefulfame-K +Palatinit & 161 & 0.686 \\
\hline Nicotine+ Acesulfame-K +Maltitol & 163 & 0.691 \\
\hline Nicotine+ Acesulfame-K +AMP & 164 & 0.696 \\
\hline Nicotine+ Acesulfame-K +Aspartame & 163 & 0.745 \\
\hline
\end{tabular}




\begin{tabular}{|l|l|l|}
\hline Nicotine+ Acesulfame-K +Furaneol & 130 & 0.792 \\
\hline Nicotine+ Acesulfame-K + $\beta$-Cyclodextrin & 498 & 0.996 \\
\hline
\end{tabular}

\section{CONCLUSION}

From the results of the present study, we have been able to classify nicotine bitterness inhibitors in three classes:

$>$ Molecules with antagonist effect (AMP) on Nicotine adsorption at the interface

$>$ molecules with negligible effect (Sucrose, Aspartame, Acesulfame-K, K-Gluconate, $\beta$ Cyclodextrin)

$>$ Molecules with enhancement effect on the adsorption of Nicotine at air/solution interface (Maltitol, Palatinit ${ }^{\circledR}$, Na-Gluconate and Furaneol)

Adsorption of nicotine is the first step in the mechanism of taste chemoreception. Based on the surface activity parameter, only AMP seems interesting.

We have also made formulation studies which were tested with ASV values. This formulation work was concluded by the classification of mixtures as follows:

Most efficient (Nicotine + Na-Gluconate, Nicotine + K-Gluconate, Nicotine + Acesulfame-K) 1:1 ratio;

(Nicotine + Na-Gluconate, Nicotine + K-Gluconate, Nicotine + Acesulfame-K, Nicotine + Sucrose) $-1: 2$ ratio;

(Nicotine + Acesulfame-K+ K-Gluconate, Nicotine + Acesulfame-K+ Na-Gluconate, Nicotine + Acesulfame-K+ Palatinit ${ }^{\circledR}$, Nicotine + Acesulfame$\mathrm{K}+$ Sucrose, Nicotine + Acesulfame-K+ Maltitol, Nicotine + Acesulfame-K+ AMP, Nicotine + Acesulfame-K+ Aspartame)- 1:1:1 ratio.

Medium efficiency (Nicotine +Maltol, Nicotine +Aspartame, Nicotine + Furaneol) - 1:1 ratio;

(Nicotine + Maltitol, Nicotine + Palatinit ${ }^{\circledR}$, Nicotine + Maltol) - 1:2 ratio;

Nicotine + Acesulfame-K+ Furaneol, Nicotine + Acesulfame-K+ Maltol) $-1: 1: 1$ ratio

\section{REFERENCES}

[1] Sweet Taste Chemoreception, Mathlouthi M, Kanters JA, Birch GG (Ed). 1993 ; Elesevier Applied Science Academic, London.

[2] Mathlouthi M.; Maciejewski C.; Serghat S.; Hooft R. W. W.; Kanters J. A.; Kroon, J. 1993. Structural studies on sweet taste inhibitors: methyl-4,6-dichloro-4,6 dideoxygalacto pyranoside. J. Mol. Struct. 291; 173-182.
[3] Mathlouthi, M.; Hutteau, F. 1999. Sweetbitter interactions and the solution properties of chlorinated sugars. Food Chem. 1999; 64;77-82.

[4] Aroulmoji, V., Hutteau, F, Mathlouthi,M., Rutledge,D.N. 2001.Hydration Properties and the Role of Water in Taste Modalities of Sucrose, Caffeine, and Sucrose-Caffeine Mixtures. J.Agric.Food Chem., 49; 4039.

[5] Aroulmoji, V, Mathlouthi, M, Richardson M O P. 2013. Solution properties and the masking of unpleasant tastes of Nicotine Sweetener - Water Mixtures. International Journal of Pharmaceutical sciences and Research, 4: 6. 2184-2207 june.

[6] Vincent Aroulmoji, Mohamed Mathlouthi, M O Portmann-Richardson. 2018. Laser Raman Spectroscopic Study on Nicotine and Nicotine-Inhibitor Mixtures in Aqueous Solution and the Role of Water in their Taste. Int. J. Adv. Sci. Eng. 4(3) 620626 March.

[7] Funasaki N, Uemura Y, Hada S and Neya S.1996. Reduction of the bitter taste intensity of propantheline bromide by cyclodextrins as predicted by surface tension measurements. J. Phys. Chemistry. 100: 16298-16301.

[8] Hutteau F., Mathlouthi M., Portmann M.O \& Kilcast D. 1998. Physicochemical and psychophysical characteristics of binary mixtures of bulk and intense sweeteners, Food Chemistry. 63(1), 9.

[9] Aroulmoji V, Mathlouthi M, Birch G G.2000. Hydration properties of $\mathrm{Na}, \mathrm{K}, \mathrm{Mg}$ gluconates and gluconate/sucrose mixtures and their possible taste effect, Food Chemistry. 70: 4. 471-482 Sep.

[10] Docoslis, A.; Giese, R. F.; Van Oss, C. J. Influence of the water-air interface on the apparent surface tension of aqueous solutions of hydrophilic solutes. Colloids Surf., B 2000, 19, 147-162.

[11] Shamil, S.; Birch, G. G.; Mathlouthi, M.; Clifford, M.N.1987. Apparent molar volumes and taste of molecules with more than one sapophore. Chem. Senses, 12, 397409.

[12] Burgard,A \& Dorr,M. 2001, Nicotine salts having improved taste, process for their preparation and their use (US Patent No: $09 / 810,815)$ 